\title{
Effectiveness of Information and Communication Technologies (ICT) on the Student's Academic Achievement at University Level
}

\author{
Ume Rubab \\ Department of Education, PMAS-Arid Agriculture University, Rawalpindi \\ ummerubab859@gmail.com
}

\begin{abstract}
The focus of this research is to explore the impact of ICT on students' academic achievement.In this research study two university, Pir Mehr Ali Shah Arid Agriculture University Rawalpindi Pakistan (PMAS_AAUR) and Fatima Jinnah Women University Pakistan (FJWU) were selected Students from both male and female gender selected with multistage random sampling techniques. There 100 sample sizes of students and 30 sample of teacher were selected. A questionnaire was used as tool of research. This instrument was validated by the panel of experts. Internal consistency coefficient (using Cronbach Alpha) was used to check the reliability and its value was 0.951 . The researcher herself collected the data conducting a survey technique. The researcher herself collected the completed questionnaires. After the interview the collected data of information were coded and analyzed with the help of the Statistical Package for Social Sciences (SPSS). The paired t-test, frequency and percentage were applied for comparison of the study.
\end{abstract}

Keywords: Information and Communication Technologies (ICT); Students' Academic Achievement

\section{Introduction}

ICT is an abbreviation for "Information and Communication Technology," which refers to the technologies that enable users to access the information they require through communication with others. It is quite similar to Information Technology (IT), but it focuses on communication tools in general rather than specific information technology. There are numerous communication technologies, including the Internet, Wi-Fi, cell phones, and other forms of communication. Incorporated are computers, mission-critical company software packages, storage devices, and audiovisual and middleware systems that enable customers to connect, market, transfer, and manage their data (Talukder, Alam, \& Apu, 2015).

Information and communication technologies are critical in establishing a new international economic system that will bring about significant changes in the world. It's been a long time since information and communication technology proliferated, developing countries have been left behind due to their interactions with developed ones. To understand information and communication technology, you need to know its core ideas (Leye, 2007).

Improvements in information and communication technology affected all sections of society, including the part related to training. The use of information and communication technologies in advanced education is transforming teaching and learning. Many educational and financial variables have prompted higher education institutions to receive e-learning. These include more prominent data access; More noteworthy correspondence via electronic offices; Simultaneous learning broadening participation and joint efforts, cost adequacy and educational change through re-enactment, virtual encounters, and realistic representations. Both mentors and learners can choose more suitable, adaptable, timely, set up, customizable, reusable, regionspecific and more cost-efficient applications (Pelliccione, 2001). 
It helps the learner straightforwardly understand complex concepts. Thus, a dynamic learning facilitator encourages and reinforces higher-level thinking (Aziz, Nawawi, \& Ariff, 2016). Comprehension of essential technologies and fundamental technological abilities are required for learners to benefit from this invention (Trpkovska, 2010).

To increase students' achievement in academics, traditional teaching styles must be updated. Computer-Aided Education (CAI) uses information and communication technology for time-independent learning and instruction, allowing students to navigate the system from their homes or laptops. CAI improves learning levels by allowing beginners to learn more in the same amount of time as classically taught students. In addition, the ICT standards make it easier for kids to learn (Hussain, Suleman, 2017). The National Education Policy 1998-2010 has also emphasised using information and communication technologies (ICTs) in the educational field. According to the National Education Policy (NEP) 1998-2010, information and communication technologies (ICTs) can be used creatively to assist instructors and learners with a diverse range of talents and from various social and economic backgrounds. Using ICT can increase the quality of teaching and educational management (Shaheen and Khatoon, 2017). Globalization has made the world a well-connected global village. The 21 st-century learner is more inventive and interested in technology.

According to Khan, Baloch, Saud, \& Fatima (2018), Information and communication technology has increased student interest. In the last few years, ICT has brought about revolutionary developments and drastically altered the scope of education. Information and communication technology and its use in most countries in Europe have assumed prime importance in education over the past decade.

Flexible management needs a budget for significant globalization, skill and industrialization for the highest pressure of civilization for individual freedom and rhetoric. It is a marvel of the microelectronics revolution in the development of broadcasting and computing (Steinmueller, 2001). The ICT part is vital in the industry to prove and manage workers to increase production. The transition to the introduction of ICT in teaching has not been fully completed yet due to the lack of information and illiteracy on the part of the Learning Director, the path to ICT in the development of the pupils offer. The teacher does not want to practice modern technologies due to unsatisfactory experience and the absence of exercise (Carnoy, 2004).

The student presentation is based on the media air and the uniqueness of the instructors and researchers. Reform is necessary in advanced education to take advantage of ICT ( Youssef, Dahmani, \& Omrani, 2015). Require providing guidance, secondary assets in ICT tools and arrangement, and be deficient in effective improvement are the primary tasks of educational leaders (Rabah, 2015). The ICT part of academic development remains unpredictable in the traditional and novice educational education around digital literacy and smooth experience. It is difficult to change the usual profits with substitutes. It relies on the real encouragement of industrial arbitrators among students and coaches (Livingstone, 2012).

Iturrioz, Cerretani, and Garay (2016) exposed that New pupils used ICT more than old students with poor educational attainment and developed psychosocial instability. More teachers used additional digital aids and ICTs in the classroom than the compulsory rate ( Tondeur, Scherer, Baran, Siddiq, Valtonen, \& Sointu 2019).An encouraging link between pupils' ideas about tablet use and learning styles relates to educational action ( Pruet, Ang, \& Farzin, 2016). Pupils think of enjoying encouragement in response to the use of technology (Muis, Ranellucci, Trevors, \& Duffy, 2015). When students use technology online, they gain healthy participation in online videos, 
which increases the efficiency of communication in English (White, 2014). The clear link between ICT use and student achievement has been extensively researched for two decades. The objectives of the study are:to find out the availability of ICT technologies in the university, to find out the effect of ICT on the academic achievement of students and to study the relationship of ICT and university students enrolled in various disciplines.

\section{Review of Literature}

Data and message technologies remain a focus of information and communication technology. Information and communication technology refers to the developments that allow data to be accessed through correspondence. It's like data innovation (IT). "Whatever the case, it is mainly centred around messaging developments. This includes the web, the remote system, PDAs, and various interchange media." Data and communication technologies have given society an enormous range of another messaging capacities (Khattak, Shah, Khan, Ali, \& Imran, 2019).

A meta-investigation learning demonstrated Sharma (2015) on consistent, students who utilized ICT-based education and tallied higher than students without PCs. Students adapted more in less time and gradually respected their periods when the guidelines were based on ICT. Meta-investigation learning demonstrated. Sharma, (2015) overall, instructive memory. Furthermore, when ICT-based education was implemented, students adapted more quickly and respected their exercises.

Bielefeldt (2005) Take advantage of global numbers from the PISA platform. The results showed that while the bivariate association between ICT openness and pupil presentation was very positive, the correlation was insignificant and insignificant when highlighting alternative effects.

Lee et al. (2003) noted: " More punctual e-learning delivers data in an indirect strategy, allowing pupils to find new data by searching for exercises and bookmarks, and besides, online mentoring support active learning practices that underline the constructivist idea. E-learning by enhancing perception, and ultimately, convenience can be availed anywhere and anywhere".

The role and utility of these technologies in the classroom and on student performance have been studied extensively. On one side, some research indicates that ICTs play a minor role in higher education (Angrist and Lavy, 2002). However, some research shows an actual impact of ICTs on student achievement (Patel, \& Shukla, 2014).

Sharma (2015) A meta-analysis study revealed that, on average, Higher test scores were achieved by pupils who received their education through information and communications technology (ICT). Furthermore, students gained more knowledge in less time and enjoyed their classrooms more when ICT-based teaching was incorporated. Sosin et al. (2004) created a database of 67 primary economics sections given by 30 lecturers at 15 US universities in 2002. The use of ICT had a considerable but minor impact on student achievement. But they found that some ICT seems to improve performance while others do not.

Fuchs and Woessman (2004) used international data from the Programme for International Student Assessment (PISA). While the bivariate link between ICT availability and student performance is robust and remarkably positive, the correlation becomes weak and unimportant when other factors of the student's environment are considered, as proven by the researchers in their study. A consensus appears to be emerging in the analysis of the effects of these methodological and technological innovations on students' attitudes toward the learning process 
and student performance. This consensus is that the appropriate use of digital technologies in higher education can significantly positively impact student behaviour and achievement levels.

Ng \& Li (2003) pointed out: "First and foremost, web-based support offers information in a non-linear manner, allowing students to discover new knowledge through browsing activities and cross-references while still learning. Second, web-based teaching encourages students to participate in active learning processes, highlighted by constructivism philosophy. Last but not least, web-based education improves comprehension by improving visualisation; and finally, it is convenient because it can be accessed at any time and from any location".

Anstine and Skidmore (2005) surveyed a pair of identical on-campus and online courses, one in Statistics and the other in Managerial Economics, offered simultaneously. After controlling for student characteristics and specific bias, they found that students who took the Statistics category exam online scored 14.1 per cent lower than those who took the exam in the traditional format. However, there was no statistically significant difference in test scores between the online and traditional formats for the Managerial Economics class.

Navarro and Shoemaker (1999) surveyed a matched pair of on-campus and online courses, one in Statistics and Managerial Economics. After taking into account student characteristics and specific bias, they reported that students in the online format for the Statistics category exam scored $14.1 \%$ lower than the traditional model. In contrast, for the Managerial Economics class, test scores in both forms were not significantly different. Terry, Lewer and Macy (2003) surveyed 240 students enrolled in a programme that offered courses in three formats: online, on-campus, and a hybrid format. According to their findings, using a standard regression model in which the final test score is the dependent variable and student characteristics are the independent variables, they found that expected test scores for students enrolled in online courses were significantly lower than those for students enrolled in campus and mixed format courses. There was no statistically significant difference when comparing exam scores between students enrolled in hybrid courses and students enrolled in campus courses.

Brown and Liedholm (2002) surveyed students in an identical pair of Principles of Economics online and face to face classes. After adjusting for student variations, they found that on-campus coordination produced $6 \%$ higher test scores than online formatting. It is believed that students' relatively better performance in on-campus classes is due to the benefit of interpersonal interactions between teacher and student. In contrast, students' relatively poor performance in the online course is due to a lack of self-discipline required for successful independent learning in an online environment.

According to Song \& Kang (2012) Leuven et al. (2004), students' performance are unrelated to the more significant usage of ICTs in education. It turns out that ICT use is consistently associated with worse student accomplishment: less study time and more time for fun with ICT. The advent of online gaming and increased communication does not equal increased achievement. Others have suggested explanations.

\section{Methodology}

The study aims to assess the impact of ICT on students' academic progress at university. 


\subsection{Population of the Study}

The study participants consisted of teachers and students of Pir Mehr Ali Shah Arid Agriculture University Rawalpindi Pakistan (PMAS_AAUR) and Fatima Jinnah Women University Pakistan (FJWU). The population of study consisted of male and female students, and teacher form 2 departments of each university universities were first department was Education and the second one Natural sciences from Education department the discipline were select of Msc, M.Phil and Ph.D. and the same discipline selected for natural sciences. The focus of this research to explore the impact of ICT on students' academic achievement, where the selection of participants for this research reflects this purpose.

\subsection{Sample}

In this research study two university, Pir Mehr Ali Shah Arid Agriculture University Rawalpindi Pakistan (PMAS_AAUR) and Fatima Jinnah Women University Pakistan (FJWU) selected were from 2 departments of each university universities were first department was Education and the second one Natural sciences from Education department the discipline were select of MSc, M.Phil and Ph.D and the same discipline selected for natural sciences students from both male and female gender selected with multistage random sampling techniques. There 100 sample sizes of students and 30 sample of teacher were selected for sample collection from each discipline with random class and with random method of selecting the students.

\subsection{Research Instrument}

A questionnaire was used as tool of research. It consisted of 30 questions designed at 5point scale (strongly disagree (SD), disagree (DA), not sure (NS), agree (A) and strongly agree (SA). The questionnaire was filled by universities personally from all the universities those included in our sample. The analysis of collected data was doing manually.

\subsection{Pilot Testing}

The research instrument was administered to 40 students which were not included in the final sample. Among them 20 were males and 20 students belonged to female category. The instrument was pilot tested for its validity. This instrument was validated by the panel of experts. Internal consistency coefficient (using Cronbach Alpha) was used to check the reliability and its value was 0.951 .

\subsection{Data Collection}

The researcher herself collected the data conducting a survey technique. Verbal and printed instructions were delivered to respondent's questionnaire fill up. It was the perception of the researcher that it reduces biased feedback from the respondents. The researcher herself collected the completed questionnaires. So a very small number of questionnaires were lost.

\subsection{Data Analysis}

After the interview the collected data of information were coded and then transferred to computer to examined and analyzed with the help of the Statistical Package for Social Sciences 
(SPSS). The paired t-test, frequency and percentage were applied for comparison of the study to check the significant difference at $5 \%$ level of probability.

\section{Results and Discussions}

\section{Availability of Learning Resources}

Table 1: Distribution of ICT sources providing by university

\begin{tabular}{|l|c|c|c|c|c|c|c|c|c|c|}
\hline \multirow{2}{*}{ ICT Sources } & \multicolumn{2}{|c|}{ SD } & \multicolumn{2}{|c|}{ D } & \multicolumn{2}{c|}{ NS } & \multicolumn{2}{c|}{ Agree } & \multicolumn{2}{c|}{ SA } \\
\cline { 2 - 13 } & $\mathbf{F}$ & $\mathbf{\%}$ & $\mathbf{F}$ & $\mathbf{\%}$ & $\mathbf{F}$ & $\mathbf{\%}$ & $\mathbf{F}$ & $\mathbf{\%}$ & F & \% \\
\hline Computer & 0 & 0.0 & 0 & 0.0 & 0 & 0.0 & 0 & 0.0 & 100 & 100 \\
\hline Internet & 10 & 7.8 & 26 & 20.3 & 20 & 15.6 & 20 & 18.6 & 20 & 15.6 \\
\hline Wireless internet & 12 & 9.4 & 22 & 17.2 & 18 & 14.9 & 27 & 21.1 & 17 & 13.4 \\
\hline Digital library & 26 & 20.3 & 18 & 14.1 & 20 & 15.6 & 17 & 13.6 & 26 & 20.3 \\
\hline Modern ICT & 14 & 10.9 & 16 & 12.5 & 21 & 16.4 & 19 & 14.8 & 30 & 23.4 \\
\hline $\begin{array}{l}\text { Recreational } \\
\text { activities }\end{array}$ & 11 & 8.6 & 18 & 14.1 & 21 & 16.4 & 21 & 16.4 & 26 & 20.3 \\
\hline
\end{tabular}

All $(100 \%)$ of the students was strongly agreed with the availability of computer in university for the students using purpose, were one-fifth (20\%) students said that we are disagree with internet facilities which is not satisfactory in our university and other side $18.6 \%$ argued that we are satisfied (agreed) with internet facilities and $15.6 \%$ seen with strongly agree response. The data also showed that $20.3 \%$ respondents said that we are strongly agree with digital library providing by university and with the same response the students argued that are strongly disagree with that statement. The majority $(23.4 \%)$ were seen strongly agree with modern ICT sources providing by the university and only $14.8 \%$ said that we are agree were the fairly $(12.5$ and $10.9 \%)$ students said that we are disagree and strongly disagree with modern ICT sources providing by university respectively.

Table 2: Compute sources providing by university for teaching purpose

\begin{tabular}{|l|c|c|c|c|c|c|c|c|c|c|}
\hline \multirow{2}{*}{ Computer Sources } & \multicolumn{2}{|c|}{ SD } & \multicolumn{2}{|c|}{ D } & \multicolumn{2}{c|}{ NS } & \multicolumn{2}{c|}{ Agree } & \multicolumn{2}{c|}{ SA } \\
\cline { 2 - 12 } & $\mathbf{F}$ & $\mathbf{\%}$ & $\mathbf{F}$ & $\mathbf{\%}$ & $\mathbf{F}$ & $\mathbf{\%}$ & $\mathbf{F}$ & $\mathbf{\%}$ & F & \% \\
\hline TU Internet & 8 & 6.3 & 25 & 19.5 & 23 & 18.0 & 25 & 19.5 & 26 & 20.3 \\
\hline TU Digital library & 13 & 10.2 & 15 & 11.7 & 21 & 16.4 & 21 & 16.4 & 30 & 23.4 \\
\hline TU Wireless internet & 12 & 9.4 & 17 & 13.3 & 21 & 16.4 & 17 & 13.3 & 33 & 25.8 \\
\hline TU Projector & 16 & 12.5 & 14 & 10.9 & 18 & 14.1 & 25 & 19.5 & 27 & 21.1 \\
\hline TU Multimedia & 0 & 0.0 & 0 & 0.0 & 0 & 0.0 & 0 & 0.0 & 100 & 100 \\
\hline
\end{tabular}

TU*: Teacher using

The data illustrated the response of the students about these resources were all (100\%) of the students strongly agree seen with using of the multimedia in class rooms, were one-fourth $(25.8 \%)$ students said (strongly agreed) that their university providing the wireless internet for teaching and study purpose and other side 13.3 and 9.4\%(strongly disagree and disagree) students said that the university never used the wireless internet. The $23.4 \%$ strongly agree seen with 
availability of digital library and one-fifth (21.1 and 19.5\%) students strongly agreed and agreed with the availability of the projector and they also mentioned that their teacher using the projector during class timing their also $12.5 \%$ students said (strongly disagree) that they never saw the projector in their class, the one-fifth $(20.3 \%)$ mentioned that we are strongly agreed with the statement of the teacher using internet for the purpose of teaching and $19.5 \%$ mentioned disagree with the statement.

Table 3: Frequency of availability of learning resources

\begin{tabular}{|l|c|c|c|c|c|c|c|c|c|c|}
\hline \multirow{2}{*}{$\begin{array}{c}\text { Learning Resources } \\
\text { of ICT }\end{array}$} & \multicolumn{2}{|c|}{ SD } & \multicolumn{2}{|c|}{ D } & \multicolumn{2}{c|}{ NS } & \multicolumn{2}{c|}{ Agree } & \multicolumn{2}{c|}{ SA } \\
\cline { 2 - 13 } & $\mathbf{F}$ & $\mathbf{\%}$ & $\mathbf{F}$ & $\mathbf{\%}$ & $\mathbf{F}$ & $\mathbf{\%}$ & $\mathbf{F}$ & $\mathbf{\%}$ & F & \% \\
\hline University lab & 19 & 14.8 & 25 & 19.5 & 15 & 11.7 & 22 & 17.2 & 19 & 14.8 \\
\hline Digital library & 15 & 11.7 & 22 & 17.2 & 20 & 15.6 & 23 & 18.0 & 20 & 15.6 \\
\hline Text books & 13 & 10.2 & 17 & 13.2 & 18 & 14.1 & 27 & 21.1 & 25 & 19.5 \\
\hline Digital projector & 12 & 9.4 & 16 & 12.5 & 22 & 17.2 & 21 & 16.4 & 29 & 22.7 \\
\hline
\end{tabular}

The data regarding learning resources is reported the availability of the ICT learning and teaching materials in university for the students were $22.7 \%$ students strongly agree with the availability of the digital project and $9.4 \%$ seen strongly dis agree, the $21.1 \%$ students said that they saw the ICT text books in university as followed the $19.5 \%$ students disagree and they mentioned that the lack of availability of ICT in university lab were $17.2 \%$ students seen agree the $18.0 \%$ students said (agree) that the ICT digital library are available, were 17.2 and $11.7 \%$ seen disagree and strongly disagree respectively.

\section{Impact of ICT on Students}

Table 4: Frequency of Impact of ICT on the student's achievements

\begin{tabular}{|c|c|c|c|c|c|c|c|c|c|c|}
\hline \multirow{2}{*}{ Impact of ICT } & \multicolumn{2}{|c|}{ SD } & \multicolumn{2}{|c|}{ D } & \multicolumn{2}{|c|}{$\mathbf{N S}$} & \multicolumn{2}{|c|}{ Agree } & \multicolumn{2}{|c|}{$\mathbf{S A}$} \\
\hline & $\mathbf{F}$ & $\%$ & $\mathbf{F}$ & $\%$ & $\mathbf{F}$ & $\%$ & $\mathbf{F}$ & $\%$ & $\mathbf{F}$ & $\%$ \\
\hline Improve knowledge & 14 & 19.9 & 17 & 13.3 & 17 & 13.3 & 27 & 21.1 & 25 & 19.5 \\
\hline Better results & 15 & 11.7 & 23 & 18.0 & 18 & 14.1 & 21 & 16.4 & 23 & 18.0 \\
\hline Improve learning & 19 & 14.8 & 17 & 13.3 & 17 & 13.3 & 19 & 14.8 & 28 & 21.9 \\
\hline $\begin{array}{l}\text { Provide advance } \\
\text { knowledge }\end{array}$ & 15 & 11.7 & 22 & 17.2 & 19 & 14.8 & 21 & 16.4 & 22 & 17.2 \\
\hline $\begin{array}{l}\text { Student teacher } \\
\text { collaboration }\end{array}$ & 10 & 7.8 & 21 & 16.4 & 23 & 18.0 & 21 & 16.4 & 25 & 19.5 \\
\hline
\end{tabular}

The impact of ICT on the students achievement is reported in Table 4 were $21.9 \%$ said (strongly agree) that ICT improve their learning but $14.8 \%$ strongly disagree with the ICT impact on students learning, were $19.5 \%$ students strongly agree with impact of ICT on improving knowledge and students and teacher collaboration but $13.3 \%$ seen disagree with the improving knowledge and improving learning and also they said that we had no idea (not sure) about that so the impact of the ICT seen in both of direction were some one said that they are strongly agree and 
other said some students said that we are strongly disagree with the impact of ICT on students achievement

\section{ICT Impact on Teacher and Students Relation}

Table 5: Frequency of ICT impact on student's and teacher relation

\begin{tabular}{|l|c|c|c|c|c|c|c|c|c|c|}
\hline \multirow{2}{*}{ ICT relation } & \multicolumn{2}{|c|}{ SD } & \multicolumn{2}{|c|}{ D } & \multicolumn{2}{c|}{ NS } & \multicolumn{2}{c|}{ Agree } & \multicolumn{2}{c|}{ SA } \\
\cline { 2 - 12 } & F & \% & F & \% & F & \% & F & \% & F & \% \\
\hline $\begin{array}{l}\text { Student teacher } \\
\text { collaboration }\end{array}$ & 16 & 12.5 & 25 & 19.5 & 21 & 16.4 & 18 & 14.1 & 20 & 15.6 \\
\hline Developing interest & 13 & 10.2 & 15 & 11.7 & 19 & 14.8 & 24 & 18.8 & 29 & 22.7 \\
\hline $\begin{array}{l}\text { Gender equally } \\
\text { benefiting }\end{array}$ & 14 & 19.9 & 23 & 18.0 & 29 & 22.7 & 15 & 17.7 & 19 & 14.8 \\
\hline
\end{tabular}

The relation of teacher and student's relation are very important factor in learning the friendly environment having different Impact and harsh relation have different Impact on students and their learning. The data in the Table 5 reported that were mostly $(22.7 \%)$ students argued that they are strongly agree with the ICT impact on the developing interest of students with their teacher and with their learning and other side the 19.9\% said (strongly disagree) that the ICT doesn't providing the equally benefiting to male and female, were the one-fifth (19.5\%) said that we are disagree with the impact of ICT on student teacher collaboration which mean ICT doesn't supporting the relation of the teacher and students. So the reported data representing the students interest towards innovation technology and the seeking the new way with the ICT.

Table 6: university providing the ICT and basic computer sources (T- test)

\begin{tabular}{|l|c|c|c|c|c|}
\hline University providing & Mean & SD & F & Sig. & t-test \\
\hline ICT Sources & 5.903 & 4.288 & 4.427 & .037 & 2.501 \\
\hline Computer & 5.039 & 3.519 & 5.260 & .022 & 2.804 \\
\hline Internet & 9.120 & 63.207 & 32.616 & .000 & 3.812 \\
\hline Wireless internet & 3.001 & 5.126 & 1.728 & .210 & 2.318 \\
\hline Digital library & 7.071 & 4.275 & 13.120 & .002 & 3.627 \\
\hline Modern ICT & 4.023 & 2.185 & 10.127 & .001 & 2.140 \\
\hline Recreational activities & 7.071 & 4.275 & 13.120 & .002 & 3.627 \\
\hline Computer Sources & 12.938 & 17.090 & 19.214 & .000 & 3.697 \\
\hline TU Internet & 7.071 & 4.275 & 13.120 & .002 & 3.627 \\
\hline TU Digital library & 4.023 & 2.185 & 10.127 & .001 & 2.140 \\
\hline TU Wireless internet & 6.418 & 3.621 & 11.332 & .001 & 3.605 \\
\hline TU Projector
\end{tabular}

The regarding data of the t-test of reported in Table 4.16 were significantly result seen in the students response about the university providing the wireless internet, modern ICT resources 
and recreational activities in ICT resources with mean of 9.120, 7.071 and 4.023 value founded, while about the computer resources which university providing were almost highly significant response stated from t-test were the mean value TU digital library (12.938), TU wireless internet (7.071), TU projector (4.023) and TU multimedia (6.418) founded from the result of research area with level of significant $0.05(95 \%)$ significant value.

Table 7: Best learning resources for student's comparison score of t-test

\begin{tabular}{|l|c|c|c|c|c|}
\hline Resources & Mean & SD & F & Sig. & t-test \\
\hline Learning Resources of ICT & .713 & 1.208 & .001 & .655 & 1.751 \\
\hline University lab & 9.938 & 11.090 & 13.214 & .000 & 2.697 \\
\hline Digital library & 2.912 & 2.015 & .312 & .522 & .819 \\
\hline Text books & .015 & .223 & 11.028 & .000 & 2.018 \\
\hline Digital projector & \multicolumn{5}{l|}{} \\
\hline ICT vs. text books Comparison & 7.061 & 4.265 & 13.160 & .001 & 3.327 \\
\hline Knowledge skills & 3.071 & 3.275 & 11.100 & .002 & 3.427 \\
\hline Learning process & 3.020 & 2.105 & 9.120 & .001 & 2.100 \\
\hline Supportive syllabus & 9.041 & 3.110 & .043 & .720 & 1.402 \\
\hline Educational planning & 10.527 & 2.436 & .509 & .425 & 1.602 \\
\hline Campus courses
\end{tabular}

The regarding data of best learning resources for student's comparison score of t-test is reported in Table 7 were highly significantly result seen in the students response were digital library mean value founded 9.938 digital project seen with mean value 0.015 , founded, while the best learning resources comparison between the text book and ICT were the respondents response found highly significant with knowledge skill with mean value 7.061, were learning process seen with mean value 3.020 the reported result mostly seen highly significant with mostly mean value 3.0 and so on the t-test were tested with $.05 \%$ (95\%) significant value.

Table 8: Impact of ICT and teacher student's relation comparison score of t-test

\begin{tabular}{|l|c|c|c|c|c|}
\hline Resources & Mean & SD & F & Sig. & t-test \\
\hline Impact of ICT on students achievement & \multicolumn{1}{|l|}{} \\
\hline Improve knowledge & .713 & 1.248 & .006 & .651 & 1.721 \\
\hline Better results & 9.138 & 6.090 & 9.214 & .000 & 2.612 \\
\hline Improve learning & 2.112 & 3.015 & .112 & .521 & .800 \\
\hline Provide advance knowledge & .035 & .223 & 7.018 & .000 & 2.000 \\
\hline Student teacher collaboration & 6.061 & 1.265 & 12.160 & .001 & 3.327 \\
\hline ICT impact on student's and teacher relation \\
\hline Student teacher collaboration & 6.041 & 5.110 & .143 & .220 & 1.402 \\
\hline Developing interest & 1.020 & 6.105 & 4.120 & .021 & 2.100 \\
\hline Gender equally benefiting & 1.071 & 1.215 & 7.100 & .022 & 3.427 \\
\hline Campus courses & 7.527 & 1.436 & 1.509 & .425 & 1.602 \\
\hline
\end{tabular}


The regarding data of Impact of ICT and teacher student's relation comparison score of ttest is reported in Table 8 were the test presented the impact of ICT on students achievement, the statement better results had seen highly significantly with mean value 9.138 and the provide advance knowledge mean value find out .035 the next one statement about the student and teacher collaboration found highly significance with mean 6.061 value the further result seen in the students response were developing interest seen significant with mean value founded 1.020, were gender equally benefiting seen with mean value 1.071, the reported data was t-test with $.05 \%$ $(95 \%)$ significant value. The reported data of the t-test solve the comparison objective of the study.

\section{Comparison based Checklist of ICT}

\begin{tabular}{|l|c|c|}
\hline Old ICT & New ICT & Expected ICT \\
\hline Computer & Laptop & Mani laptop \\
\hline Radio & Television & $3^{\text {rd }}$ screen \\
\hline Phone & Mobile & Smart mobile \\
\hline Telegram & Internet & SMS \\
\hline Projector & Multimedia & Smart media \\
\hline Linux & Window & New version Window \\
\hline Typing machine & Printer & Advance printer \\
\hline Old Software & New software & Advance software \\
\hline
\end{tabular}

The ICT upgrading with the modernization of technology by the experiment of old technology the researcher discovered new ICT application and adoption process of them which further provide the facilities for students in learning and creating expertise for better future the ICT always showed the impact on the generation of the era as like modern technology make easy the access ability of knowledge and transferring of thought, opinion and idea with everyone. The expected technology is directly product of the old and new technology and adoption and absorption of this technology in society. The new technology provides the new way of teaching and learning to university students and providing the accessibility for learning of new idea, skill and knowledge.

\section{Conclusion}

All of the students was strongly agreed with the availability of computer in university for the students using purpose, but some students said that we are disagree with internet facilities which is not satisfactory in our university. The majority of students strongly agree with modern ICT sources providing by the university and only some students said that we are disagree and strongly disagree with modern ICT sources providing by university respectively. All students strongly agreed with the use of multimedia in the classrooms, according to the data. The data regarding learning resources is reported the availability of the ICT learning and teaching materials in university for the most of the students were agree with the availability of the digital project and students said that they saw the ICT text books in university as followed some students disagree and they mentioned that the lack of availability of ICT in university lab. Most of students said (agree) that the ICT digital library are not available in the university. The impact of ICT on the students achievement is reported most of the students agreed that ICT improve their learning and 
ICT have impact on students learning, students strongly agree with impact of ICT on improving knowledge and students and teacher collaboration but some students said that we had no idea (not sure) about that so the impact of the ICT seen in both of direction were some one said that they are strongly agree and other said some students said that we are strongly disagree with the impact of ICT on students achievement. The relation of teacher and student's relation are very important factor in learning the friendly environment having different Impact and harsh relation have different Impact on students and their learning. The data reported that mostly students argued that they are strongly agree with the ICT impact on the developing interest of students with their teacher and with their learning and other side the most of the students said that the ICT doesn't providing the equally benefiting to male and female. Majority of the students were disagree with the impact of ICT on student teacher collaboration which mean ICT doesn't support the relation of the teacher and students. So the reported data representing the students interest towards innovation technology and the seeking the new way with the ICT. The regarding data of the t-test of reported were significantly result seen in the students response about the university providing the wireless internet, modern ICT resources and recreational activities in ICT resources, while about the computer resources which university providing were almost highly significant response stated from t-test were the mean value TU digital library (12.938), TU wireless internet (7.071), TU projector (4.023) and TU multimedia (6.418) founded from the result of research area with level of significant 0.05 (95\%) significant value. The regarding data of best learning resources for student's comparison score of t-test is reported were highly significantly result seen in the students response were digital library mean value founded 9.938 digital project seen with mean value 0.015 , founded, while the best learning resources comparison between the textbook and ICT were the respondents' response found highly significant with knowledge skill with mean value 7.061. The regarding data of Impact of ICT and teacher student's relation comparison score of t-test is reported the test presented the impact of ICT on students achievement, the statement better results had seen highly significantly with mean value 9.138 and statement about the student and teacher collaboration found highly significance with mean 6.061 value.

\section{Discussion}

The current study shows some students said that we are disagree with internet facilities which is not satisfactory in our university. Some students agree with modern ICT sources providing by the university and some students said that we are disagree and strongly disagree with modern ICT sources providing by university respectively. This idea supported by Ishaq, et al. (2020). Students should have access to the internet with high bandwidth. The current study shows the data regarding learning resources is reported the availability of the ICT learning and teaching materials in university for the most of the students were agree with the availability of the digital project and students said that they saw the ICT text books in university as followed some students disagree and they mentioned that the lack of availability of ICT in university lab. Most of students said that the ICT digital library are not available in the university. This idea is supported by Shaikh, \& Khoja, (2011) The survey found that while ICT is widely utilised in Pakistan's large cities (Karachi, Lahore, Peshawar, Quetta, Islamabad, etc. ), it is only used 50\% of the time when compared to the near future (2019) or developed countries. It is also assumed that educational/research ICTs will be heavily used in the near future, yet their current use is just $50 \%$. The current study shows that the impact of ICT on the students' achievement is reported most of 
the students agreed that ICT improve their learning and ICT have impact on students learning, students strongly agree with impact of ICT on improving knowledge. This idea supported by Sharma (2015) A meta-analysis study revealed that, on average, students who used ICT-based education scored higher than students who did not have computers. Students learnt more in less time and enjoyed their classes more when ICT was used. This study results shows that the data illustrated the response of the students about these resources were some students said that the university never used the wireless internet. They agreed with the availability of the projector and they also mentioned that they never saw the projector in their class. This idea supported by Ishaq, et al. (2020) Both faculty and administration should make use of (ICT) resources that can assist students in achieving higher levels of academic success.

\section{Recommendation}

1. The study was conduct in university area for the purpose of ICT impact were result showed that the university should be provide the essential tool of the ICT.

2. The gender difference so the teacher should be teaching them with equal opportunity.

3. The teacher seen with low utilization of internet in class so the teacher should be concentrate on internet facilities.

4. The digital library seen with low ratio in university so the university should be provides the digital library for students using purpose.

5. The teacher and students' collaboration seen with minute ratio so the collaboration between the students and teacher should be rise.

6. Wireless internet seen with low ratio in university so university should be provides the facilities for students.

\section{References}

Angrist, J., \& Lavy, V. (2002). New evidence on classroom computers and pupil learning. The Economic Journal, 112(482), 735-765.

Anstine, J., \& Skidmore, M. (2005). A small sample study of traditional and online courses with sample selection adjustment. The Journal of Economic Education, 1(2),107-127.

Aziz, N. D., Nawawi, A. H., \& Ariff, N. R. M. (2016). ICT evolution in facilities management (FM): building information modelling (BIM) as the latest technology. Procedia-social and behavioral sciences, 234, 363-371.

Bielefeldt, T. (2005). Computers and student learnings: Interpreting the multivariate analysis of PISA 2000. Journal of Research on Technology in Education, 37(4), 339-347.

Brown, B. W., \& Liedholm, C. E. (2002). Can web courses replace the classroom in principles of microeconomics?. American Economic Review, 92(2), 444-448.

Carnoy, M. (2004). ICT in education: Possibilities and challenges. Inaugural Lecture of the UOC, 2005. 
Cerretani, P. I., Iturrioz, E. B., \& Garay, P. B. (2016). Use of information and communications technology, academic performance and psychosocial distress in university students. Computers in Human Behavior, 5(6), 119-126.

Hussain, I., \& Suleman, Q. (2017). Effects of Information and Communication Technology (ICT) on Students' Academic Achievement and Retention in Chemistry at Secondary Level. Journal of Education and Educational Development, 4(1), 73-93.

Ishaq, K., Azan, N., Zin, M., Rosdi, F., Abid, A., \& Ijaz, M. (2020). The impact of ICT on students' academic performance in public private sector universities of Pakistan. International Journal of Innovative Technology and Exploring Engineering (IJITEE), 9(3), 1117-1121.

Khan, N., Baloch, M. A., Saud, S., \& Fatima, T. (2018). The effect of ICT on CO 2 emissions in emerging economies: does the level of income matters? Environmental Science and Pollution Research, 25(23), 22850-22860.

Khattak, H. A., Shah, M. A., Khan, S., Ali, I., \& Imran, M. (2019). Perception layer security in Internet of Things. Future Generation Computer Systems, 100, 144-164.

Leye, V. (2007). UNESCO, ICT corporations and the passion of ICT for development: modernization resurrected. Media, Culture \& Society, 29(6), 972-993.

Livingstone, S. (2012). Critical reflections on the benefits of ICT in education. Oxford review of education, 38(1), 9-24.

Muis, K. R., Ranellucci, J., Trevors, G., \& Duffy, M. C. (2015). The effects of technologymediated immediate feedback on kindergarten students' attitudes, emotions, engagement and learning outcomes during literacy skills development. Learning and Instruction, 3(8), $1-13$.

Navarro, P., \& Shoemaker, J. (1999). The power of cyberlearning: An empirical test. Journal of computing in Higher Education, 11(1), 29-54.

Ng, J. J., \& Li, K. X. (2003). Implications of ICT for knowledge management in globalization. Information management \& computer security. 11,167-174.

Patel, D. J., \& Shukla, K. K. (2014). Challenges and opportunities for ICT initiatives in agricultural marketing in India. Oriental Journal of Computer Science and Technology, 7(3), 377-381.

Pelliccione, L. (2001). Implementing innovative technology: Towards the transformation of a university (Doctoral dissertation, Curtin University).

Pilat, D., Lee, F., \& Van Ark, B. (2003). Production and use of ICT: A sectoral perspective on productivity growth in the OECD area. OECD Economic Studies, 2002(2), 47-78.

Pruet, P., Ang, C. S., \& Farzin, D. (2016). Understanding tablet computer usage among primary school students in underdeveloped areas: Students' technology experience, learning styles and attitudes. Computers in Human Behavior, 59(5), 1131-1144.

Rabah, J. (2015). Benefits and Challenges of Information and Communication Technologies (ICT) Integration in Québec English Schools. Turkish Online Journal of Educational Technology-TOJET, 14(2), 24-31. 
Shaheen, S., \& Khatoon, S. (2017). Impact of ICT Enriched Modular Approach on Academic Achievement of Biology Students. Journal of Research \& Reflections in Education (JRRE), 11(1),49-59.

Sharma, H. K. (2015). Role of ICT in Improving the Excellence of Education. International Journal on Computer Science and Engineering, 7(8), 78.

Shaikh, Z. A., \& Khoja, S. A. (2011). Role of ICT in Shaping the Future of Pakistani Higher Education System. Turkish Online Journal of Educational Technology-TOJET, 10(1), 149161.

Song, H. D., \& Kang, T. (2012). Evaluating the Impacts of ICT Use: A Multi-Level Analysis with Hierarchical Linear Modeling. Turkish Online Journal of Educational Technology-TOJET, 11(4), 132-140.

Sosin, K., Lecha, B. J., Agarwal, R., Bartlett, R. L., \& Daniel, J. I. (2004). Efficiency in the use of technology in economic education: Some preliminary results. American Economic Review, 94(2), 253-258.

Steinmueller, W. E. (2001). ICTs and the possibilities for leapfrogging by developing countries. Int'l Lab. Rev. 140(2001),193-210.

Talukder, M. S., Alam, M. J., \& Apu, M. A. I. (2015). The impact of ICT on students'performance: a case study on undergraduate university students. Manarat International University Studies, 4(1), 137-147.

Terry, N., Lewer, J. J., \& Macy, A. (2003). The efficacy of alternative instruction modes in economics. Available at SSRN 392561.

Tondeur, J., Scherer, R., Baran, E., Siddiq, F., Valtonen, T., \& Sointu, E. (2019). Teacher educators as gatekeepers: Preparing the next generation of teachers for technology integration in education. British Journal of Educational Technology, 50(3), 1189-1209.

Trpkovska, M. A. (2010, June). A study of information technology use among students at South East European University. In Proceedings of the ITI 2010, 32nd International Conference on Information Technology Interfaces (pp. 257-262). IEEE.

White, H. (2014). Metahistory: The historical imagination in nineteenth-century Europe. JHU Press.

Woessmann, L., \& Fuchs, T. (2004). Computers and student learning: Bivariate and multivariate evidence on the availability and use of computers at home and at school. Available at SSRN 619101.

Youssef, A. B., Dahmani, M., \& Omrani, N. (2015). Information technologies, students'e-skills and diversity of learning process. Education and Information Technologies, 20(1), 141159. 